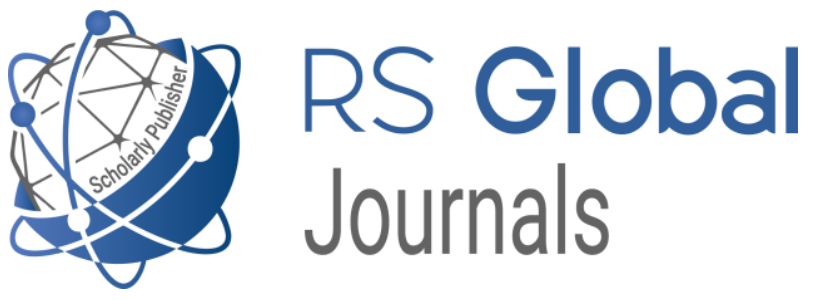

Scholarly Publisher

RS Global Sp. z O.O.

ISNI: 0000000484952390

Dolna 17, Warsaw, Poland 00-773

Tel: +48226022703

Email: editorial_office@rsglobal.pl

JOURNAL International Journal of Innovative Technologies in Social Science

p-ISSN

2544-9338

e-ISSN

2544-9435

PUBLISHER

RS Global Sp. z O.O., Poland

ARTICLE TITLE Evaluation of the Psychotrauma as a Result of Sexual Abuse

AUTHOR(S) Kozlova Anna Georhiivna

Kozlova A. G. (2020) Evaluation of the Psychotrauma as a Result

ARTICLE INFO of Sexual Abuse. International Journal of Innovative Technologies in Social Science. 6(27).

doi: $10.31435 /$ rsglobal_ijitss/30092020/7151

DOI

https://doi.org/10.31435/rsglobal_ijitss/30092020/7151

RECEIVED

13 August 2020

ACCEPTED

14 September 2020

PUBLISHED

16 September 2020

LICENSE

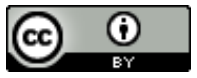

This work is licensed under a Creative Commons Attribution

4.0 International License.

(C) The author(s) 2020. This publication is an open access article. 


\title{
EVALUATION OF THE PSYCHOTRAUMA AS A RESULT OF SEXUAL ABUSE
}

\author{
Kozlova Anna Georhiivna, \\ post-graduate student of the Department of Psychodiagnostics and Clinical Psychology \\ Taras Shevchenko National University of Kyiv, Ukraine, Kyiv, \\ ORCID ID https://orcid.org/0000-0002-7538-450X
}

DOI: https://doi.org/10.31435/rsglobal_ijitss/30092020/7151

\section{ARTICLE INFO}

Received 13 August 2020

Accepted 14 September 2020

Published 16 September 2020

\section{KEYWORDS}

Psychotrauma, stages of the experiencing psychotrauma, research protocol, children, victims of sexual violence, psychological expertise.

\begin{abstract}
The investigation of crimes against the sexual integrity of children requires the use of special psychological knowledge, which is due to the specifics of the most illegal actions and characteristics of children. Background is in the absence of developed protocols for investigating cases of sexual abuse of children. The given information of the article is based exclusively on the results of practical experience of the psychological expertise's. The article describes the author's approach to the study of children - victims of sexual violence and presents the results of research protocol for assessing the signs of psycho-trauma of a child due to sexual violence.
\end{abstract}

Citation: Kozlova A. G. (2020) Evaluation of the Psychotrauma as a Result of Sexual Abuse. International Journal of Innovative Technologies in Social Science. 6(27). doi: 10.31435/rsglobal_ijitss/30092020/7151

Copyright: (C) 2020 Kozlova A. G. This is an open-access article distributed under the terms of the Creative Commons Attribution License (CC BY). The use, distribution or reproduction in other forums is permitted, provided the original author(s) or licensor are credited and that the original publication in this journal is cited, in accordance with accepted academic practice. No use, distribution or reproduction is permitted which does not comply with these terms.

Introduction. The historical analysis of the problem of violence against children is quite complex. The main reason for the difficulties is the lack of reliable facts from the history of childhood at different stages of development of society. Historians are usually more interested in the causal links of global events, while ignoring or greatly distorting the facts about childhood in the periods under consideration. Official historical biographies usually idealize childhood or subjectively cover only a certain aspect of human life. Historical sociologists produce most theories to explain changes in childhood, not appreciating the complex with no family.

A review of the literature. Sexual violence against children is a special type of crime that focuses on the relationship between the offender and his victim, which leads to the negative consequences of traumatizing the child and changing the perspective of his personality. Direct study of such interaction engaged Antonian Y. M., Voronova Y. U., Ryvman D. V., Skryta I. G. and others.

American researchers define sexual abuse of children, as any sexual experience between a child up to 16 years (by sources - to 18) and the person at least 5 years older than the child.

Sexual violence against children includes many actions: forcing or encouraging a child to have sexual contact with the body of an adult or child, forcing a child to expose, engaging in orgies and rituals that are accompanied by sexual acts [2].

The practice of pre-trial and judicial investigation testifies in favor of the need to conduct psychological research, which would confirm the existence of violence against a child. After analyzing the specifics of committing sexual crimes against children, we came to the conclusion that when conducting psychodiagnostic research does not take into account their specificity, which significantly affects the level of depth of trauma to the child. 
Mental trauma is a change in mental activity caused by external factors (events) that lead to maladaptation of the individual, or disorders of the normal functioning of the psyche and the body as a whole.

The stages of a child's experience of psychotrauma are: 1 . Shock ( $2-3$ days) - at this stage there is an increase in emotional stress, due to the emotional signal of the individual about the situation that has occurred;

2. Stage of personality disorganization - this phase is critical, because after it begins the process of recovery, or fixation on the injury and the subsequent development of post-stress disorders (from 1 day to 2 weeks);

3. Stage of adaptation ( $2-4$ weeks $)$ - there is a suppression of the emotional reaction. Importantly says Bertovsky L.V. that after 15 days the child's memories of the event begin to fade [1]. Also at the stage of adaptation is the inclusion of protective mechanisms of the individual that allow the child to cope and adapt;

4. Stage of recovery (from 4 weeks to several months) - in fact, this is the final process of adaptation, but it does not always go through the personal level, so this stage has a significant impact on the formation of personality.

Research results. To establish the facts of sexual offenses against children in criminal proceedings for the study raise the question: "Are there signs of psychological experiences of child psychotrauma situation? If so, how do they manifest?".

The psychologist cannot state or deny the fact of a sexual crime against a child, as the establishment of such a fact is within the competence of the investigative bodies and the court. But psychological research or expertise can establish psychological characteristics of the child, which may be inherent to the situation psychotraumatic experience, including as a result of staying in a situation of sexual violence. If a child has signs of experiencing a traumatic situation and these signs may be causally related to crimes against the child's sexual integrity, the psychologist indicates this when answering the question.

Performance features of crimes are the psychological characteristics, but the algorithm for their consideration during the psychodiagnostic we don't have. Therefore, we will develop a threedimensional model for assessing a child's experience of psychotrauma as a result of violence, taking into account all the factors that may influence the process of conducting such research. The use of a three-dimensional model is necessary after a psychodiagnostic research and a special interviewing of children - victims of violence.

Using a three-dimensional model, the psychologist can: determine the degree of individual impact of the situation of violence on the child; provide written opinions in a structured way; provide psychological recommendations for further psychological work with the child.

Protocol of the dimensional model. The first perspective of assessment in the threedimensional space of the model involves the assessment of social threat to the child, this includes 6 indicators, namely: threat to life and health, the number of encroachments, during which time the encroachments took place, who committed the crime, where the crime took place, how much time elapsed from the moment of the encroachment to the diagnosis. Each indicator is measured by 3-point scale according to certain characteristics. The first level helps the psychologist to determine how pronounced the child's symptoms of a traumatic situation are and whether they are related to sexual violence (the existence of a causal connection). Information on the assessment of the level of social threat to a child, psychologist receives from a special interview process and analyzes materials of the criminal proceedings (in cases where they are present).

The second perspective of the model involves assessing the level of trauma. Here included 5 indicators: stage of psychotrauma, levels of manifestation of psychotrauma: emotional, personal, behavioral, somatic. Each indicator is also evaluated on a 3-point scale in accordance with certain characteristics. This dimension allows the psychologist to answer the question: "Are there psychological signs of a child experiencing a traumatic situation? If they are present, then in what they are manifested." The psychologist assesses the level of psychotrauma based on the results of psychodiagnostic research, psychological history and characteristics of the child (if they are present).

The third perspective of the model involves assessing the level of understanding of the situation of violence. This includes 4 indicators: the child's understanding of the situation, the ability to resist, the peculiarities of the reproduction of events, the child's age at the time of the study. Each 
indicator is also evaluated on a 3-point scale in accordance with certain characteristics. Assessment of the third dimension helps the psychologist to answer the question: "Is the child able to take into account its age, emotional state, individual psychological characteristics, level of mental development and conditions of the microsocial environment to perceive the circumstances relevant to the case and give appropriate testimony?", "What are the psychological features of the child's reproduction of events?", As well as "Is the child able, based on the level of his mental development, individual psychological characteristics and emotional state, to properly understand the nature and significance of actions and resist. The psychologist receives information about the third dimension as a result of the analysis of special interviews and materials of the criminal proceedings (if they are present).

Analysis of results by a three-dimensional model. The experimental group included 32 people aged 4 to 10 years, who were prosecuted and recognized as victims of sexual violence. The analysis of the results of the study according to the three-dimensional model revealed that $79 \%$ had an average level of threat to the child, $14 \%$ - high, 7\% — low. Assessment of the level of trauma: $76 \%$ - low, $19 \%$ - medium, 5\% - high. Assessment of the level of understanding of the situation of violence: 91\% - medium, $9 \%$ - low, $0 \%$ - high.

Conclusions. According to the results of the study, we can say that the majority of the group has an average level of impact of the situation of violence on the child's personality. Such results are due to age - lack of understanding of the situation of violence leads to "conservation" of trauma and self-recovery, while the consequences of the event will be manifested in adulthood and affect the course of life.

\section{REFERENCES}

1. Bertovsky L. V. (2015) Features of questioning children under 7 years. RUDN Journal of Law. №3, p. 113-133. (In Russian).

2. Zinov'eva N. O., Mihajlova N. F. (2003) Psychology and psychotherapy of violence. Child in crisis. SanktPeterburg: Rech, 248 p. 